\title{
On the Supposed Origin of Life in Solutions of Colloidal Silica.
}

\author{
BY
}

SYDNEY G. PAINE.

With Plate IX.

THE origin of life is at present in entire obscurity, and it would seem

1 that our knowledge of chemistry and physics must advance considerably before any real light can be thrown upon it.

It is a question which lends itself more to speculation than to laboratory practice, but it is hoped that one day we may be in a position to investigate experimentally the phenomena concerned in the change from the non-living to the living state.

Except for certain investigations in the first half of the nineteenth century, the only experimental work which definitely had as its object the realization of this change is that of the late Dr. Charleton Bastian. Since the appearance of his first publication on the subject in 1870 until the time of his death, Dr. Bastian held firmly to the view that living organisms may arise de novo from non-living materials. During the past twenty years he has supported his view by numerous experiments in which he describes the development of organisms under conditions calculated to exclude all possibility of infection by a living germ.

The results of this work are to be found in three monographs by this author (1), and in the pages of Nature (2).

The method of experiment is described fully at page 30 of 'The Origin of Life', and consists of enclosing in special tubes very dilute solutions of colloidal silica mixed either with phosphoric acid or with some form of colloidal iron; after sealing, the liquids are carefully sterilized by intermittent sterilization at $100^{\circ} \mathrm{C}$. or by short exposures to temperatures of $\mathrm{I} 20^{\circ} \mathrm{C}$. to $\mathrm{I} 35^{\circ} \mathrm{C}$. Thus prepared, the tubes are exposed to light at an east window for periods varying from six months to two years. During this time a small deposit collects at the bottom of each tube, and the examination of this is made by removal with a fine pipette on to a microscope slide, or the liquid is sometimes centrifuged and the deposit examined microscopically.

[Annals of Botany, Vol. XXX. No. CXIX. July, 1916.] 
According to Dr. Bastian many forms of Bacteria, Torulae and fungal hyphae are to be found in the amorphous matrix which this deposit always presents.

Dr. Bastian claims that successful infections can be made of these upon various nutrient media. In this he is supported by A. and A. Mary (3), and also by A. H. Drew (4), who, according to Dr. Bastian, has succeeded by the use of tyrosine in cultivating bacilli more or less freely. On the contrary, J. Wright in New York (4) repeating these experiments has obtained similar structures, but has been unable to obtain growth of these on artificial media.

In I9I3 Dr. Bastian showed some of his supposed organisms to many biologists, amongst others to Professor Farmer and Professor Blackman at the Imperial College of Science and Technology, who, in fairness to him and in view of the fact that his later methods made sterility more probable than was the case in some of his earlier experiments, desired that a careful repetition of the experiments should be made. At their instigation the author commenced, as stated in a note in Nature (5), an investigation in order to discover if possible the origin and nature of the organisms described.

Experiments have been carried on now for more than two years, and altogether eighty-five tubes have been under examination. These tubes were prepared in accordance with the directions given by Dr. Bastian in his book 'The Origin of Life', and contained a mixture of dilute solutions of colloidal silica, ammonium phosphate and phosphoric acid, or a mixture of colloidal silica with liquor ferri pernitratis; the former he speaks of as the colourless solution, the latter as the yellow solution. In addition, during last year a few experiments were made with mixtures of colloidal iron, potassium ferrocyanide and sodium silicate, which Dr. Bastian found to be specially fruitful. The conditions of experiment have followed as closely as possible those of Dr. Bastian's experiments; the tubes were sealed and sterilized according to his instructions and exposed to light at an east window.

When examined six to eight months after sterilization, the majority of the tubes showed deposits consisting mainly of an amorphous mass of silica together with minute shining plates, also presumably of silica.

There also occur very frequently small highly refracting spheres either scattered singly in the amorphous matrix or collected together in masses. They are in size and appearance very similar to the bodies described by Dr. Bastian as fungus germs.

A very large deposit of these bodies was found in a ro per cent. solution of sodium silicate which remained tightly stoppered in a Ioo c.c. flask from February to October of last year. The deposit had formed a loose layer 3 to $4 \mathrm{~mm}$. thick at the bottom of the flask. The microscopic appearance of these bodies is shown in the accompanying photograph 
(see P1. IX, Fig. 1), and seems to be identical with that figured several times in Dr. Bastian's book on 'The Origin of Life,' notably with that in Pl. I, Figs. 2 and 6 ; Pl. II, Fig. 8 ; Pl. IV, Fig. 23 ; and Pl. X, Fig. 57.

After microscopical examination the remainder was collected on a tared filter, and when dried at $100^{\circ} \mathrm{C}$. weighed $14.4 \mathrm{mgm}$. Analysis showed it to consist of 38.9 per cent. $\mathrm{SiO}_{2}$, a very small trace of $\mathrm{Fe}_{2} \mathrm{O}_{3}$, and a trace of $\mathrm{Na}_{2} \mathrm{O}$. No organic matter was present, as shown by absence of charring on heating with $\mathrm{H}_{2} \mathrm{SO}_{4}$. The remaining 60 per cent. was presumably water. When heated the transparency of the material was lost, and the particles broke up to a fine white powder. The author concludes that they were little solid spheres of hydrated silica deposited from colloidal solution.

In some of the tubes larger rounded bodies have occurred; a mass of these surrounded by an amorphous deposit is shown in Pl. IX, Fig. 2. When crushed under the cover-slip these bodies separated from the matrix and were found to be flat discs or sacs of round or oval contour, varying in diameter from $10 \mu$ to $60 \mu$. Being perfectly transparent objects they proved very difficult to photograph, but eventually a fair representation was obtained by varying the intensity of light in different parts of the field. The results are given in Figs. 3 and 4.

Many of the bodies appear to have budded and have much the appearance of yeast cells. This is probably caused through cohesion of the smaller with the larger particles. These bodies are probably little discs or solid spheres rather than hollow sacs or cells, and any yeastlike budding would thus seem to be out of the question. Evidence for this view is afforded by one or two specimens shown in Figs. 3 and 4 , which have been broken by pressure on the cover-glass in mounting, and which exhibit irregular fracture strongly indicative of such solid nature. It is not suggested that these large bodies were exactly the same as those described by Dr. Bastian as Torulae, but they seem to differ only in point of size from those which he figures in Pl. VIII, Figs. 45 and $47 \mathrm{~B}$ of his book.

The author is indebted to the late Dr. Bastian for supplies of materials used by him, and further for the opportunity he gave the author of seeing some of his own preparations and of opening and examining three of his own tubes from a series of experiments which had given him positive results.

From one of these tubes sealed July 8, I9I4, opened in December, I9I4, a large number of round bodies were obtained from a gelatinous deposit which had collected on the sides of the tube just above the level of the liquid. As first examined they had the appearance shown in Fig. 5.

By simple manipulation with a needle a few of these were separated from the amorphous residue, washed well with water, and allowed to dry on a thin glass slide, upon which they were heated to dull redness.

As the result of this treatment no charring was observed, and the 
bodies seemed to remain entirely unaltered. They were then mounted in a resinous medium (euparal) and examined closely with a high power objective. They appeared as thick-walled hollow spheres apparently of silica, the walls bearing pits very similar to those in the walls of the so-called stone cells of the pear. The pitting is well shown in the original photograph, but this detail will probably disappear in the process of reproduction. In Fig. 6 three of these objects are seen in juxtaposition, and beneath these several fragments of others which have been broken by pressure on the cover-glass during mounting. The objects were very brittle and, as stated above, were hollow; to this fact is due the apparent blackness of one of the spheres from which the air was not expelled by the mounting fluid.

Comparison of these preparations with Dr. Bastian's Figs. 5 and 35 in 'The Origin of Life ' points to the conclusion that the bodies under investigation are identical with those figured by him. The granular contents of which he speaks in the description of Fig. 5 appear to the author to be only pits in the walls such as he has observed in his own preparations.

The method of formation of these bodies is so far obscure.

In contrast, the method of formation of the other silico-morphs mentioned above, namely the small solid spheres and the flat discs, is not difficult of explanation. These bodies have probably been built up by slow deposition from a colloidal solution upon minute specks of solids, or upon nuclei composed of the first aggregates which have separated from such solution. That silica is deposited slowly from colloidal solutions upon solids immersed in them is well shown in Pl. IX, Fig. 7. This specimen was found in a bottle of colloidal silica which had been left undisturbed for twenty-one months. The nucleus for deposition in this case seems to have been a cotton fibre which in course of time has become irregularly coated with a hard glass-like mass of silica. Fine markings visible in the original photograph, which appear as striae in the deposit, will probably be lost in reproduction.

Besides the forms already mentioned, there occurred in most of the tubes very fine threads with something of the appearance of fungal hyphae. These have been well figured in a recent publication by Professor Moore and W. G. Evans (Proc. Roy. Soc., I9I5, B., 89, p. I 7), who have shown that they result by slow decomposition from metastable solutions of inorganic colloids. That they are not threads of fungal mycelium is very apparent when, while under observation with a low power objective, an attempt is made to draw them across the slide with a fine pointed needle. Thus in several experiments of this kind it was observed that the thread is not carried along or bent by the needle, as would be the case with a fungal hypha, but is ruptured by the needle at the point of contact, the substance of the thread being drawn out in a streak of gelatinous material.

Moreover, when attempts were made to stain these threads it was 
found that they stained uniformly with various dyes, but showed none of the contents which are so characteristic of living fungal hyphae. It is clear that the threads in question are merely deposits of colloidal material simulating only in a slight degree the hyphae of a fungus.

The author has never obtained in sterilized tubes any growths of a typical fungal or Torula-like nature, and no growth has ever developed in nutrient media which have been inoculated from the tubes at the time of opening. In cases, however, where the tubes were not sterilized at all, or where they were allowed to stand for a week before being sterilized, there have usually been found rudimentary mycelia of a very crumpled appearance. These were obviously dead, and surrounded by a deposited layer of silica. In most of these cases it is fairly easy to trace the spore from which the mycelium has developed, although this is not always possible. Fig. 8 represents one of these growths from a tube which was prepared, sealed, and left eight days before being sterilized by intermittent sterilization at $100^{\circ} \mathrm{C}$. Here the spore is quite obvious, and there can be no doubt that similar growths must inevitably be introduced with the solutions if these should have been made even a few hours before being filled into the tubes.

The growth shown in Pl. IX, Fig. 9, was observed in a tube containing colloidal silica and ammonium phosphate which had been opened and left standing for five months. The microscopic appearance is strikingly similar to that represented in many of Dr. Bastian's figures. At the time of observation this fungus was dead and the cells, when treated with Delafield's haematoxylin, exhibited contents or some remains of organic material such as are typical of the disorganized contents of a fungal mycelium.

A very similar growth was also obtained in a solution of colloidal silica during the process of dialysing in a parchment dialyser which had not been sterilized.

That growths obtained under these conditions so closely resemble those found by Dr. Bastian would seem to suggest that the conditions under which circumstances forced him to labour were not always conducive to perfect sterility of his solutions.

All these observations support the view which has frequently been urged by others that the organisms described by Dr. Bastian were either purely inorganic silico-morphs, or else were produced by the deposit of silica on the surface of dead fungal hyphae or yeast cells which had developed in the solutions before these were filled into the tubes and sterilized.

This work was completed and ready for publication at the time of Dr. Bastian's death, and it is a matter for regret that he is no longer with us to take up the challenge. His work has aroused considerable interest in certain quarters, and it therefore seems advisable to place these observations on record. 


\section{SUMMARY.}

I. The experiments of Dr. Bastian have been repeated.

2. In all, eighty-five tubes of colloidal silica have been examined.

3. Forms, which in a slight degree resembled organisms, have been found amongst the amorphous deposit which collected in the tubes, and these have been shown to be composed of silica.

4. These bodies are thought to be identical with some of the so-called fungus germs described by the late Dr. Bastian.

5. It is concluded that the forms resembling organisms, described by Dr. Bastian as evidence of spontaneous generation of life, were in part purely inorganic simulacra formed by slow deposition of silica from colloidal solution, and in part depositions of silica upon dead fungal hyphae which had developed in the solutions before these were filled into the tubes and sterilized.

\section{REFERENCES.}

1. The Nature and Origin of Living Matter, 1905. The Evolution of Life, 1907. The Origin of Life (Second Edition), I9I3.

2. Nature, Jan. 22, and Dec. 24, I9I4; July I 5 , I91 5.

3. Le Médecin (Brussels), Oct. 3I, I9I3, and Jan. I5, I9I4.

4. Nature, vol. xciv, I9I 4, p. 466.

5. Nature, Feb. I2, I9I4.

\section{EXPLANATION OF FIGURES IN PLATE IX.}

Illustrating Mr. Paine's paper on Colloidal Silica.

Fig. I. Deposit of small spheres of silica from a solution of sodium silicate.

Fig. 2. Deposit from a tube of colloidal silica, ammonium phosphate and phosphoric acid.

Fig. 3. Discs of silica separated from Fig. 2 by pressure between the cover-slip and the slide upon which the deposit was mounted in water.

Fig. 4. The same more highly magnified.

Fig. 5. Deposit of gelatinous silica containing hollow spheres of silica removed from the sides of one of Dr. Bastian's tubes.

Fig. 6. Three of the same objects separated from the amorphous matrix, heated on a slide and mounted in euparal. (The dark object contains a bubble of air.) Fragments of others appear in the lower half.

Fig. 7. Cotton fibres upon which silica has been laid down by deposition from a solution of colloidal silica.

Fig. 8. Dead fungal mycelium from a tube which had remained for a week before sterilization.

Fig. 9. Fungi and spheres of silica from a tube of colloidal silica, ammonium phosphate and phosphoric acid, which was not sterilized. 
Annals of Botany,
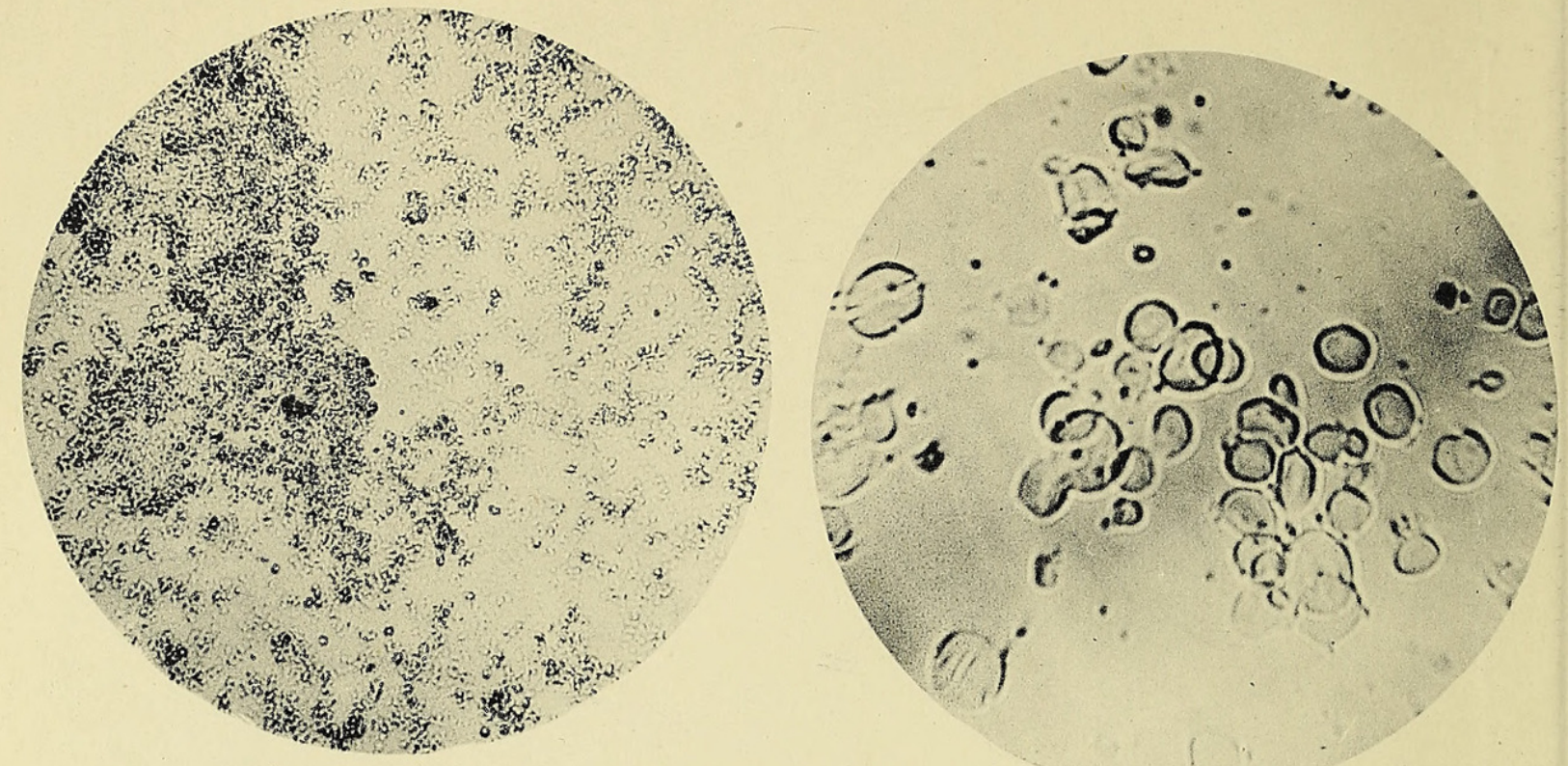
1.
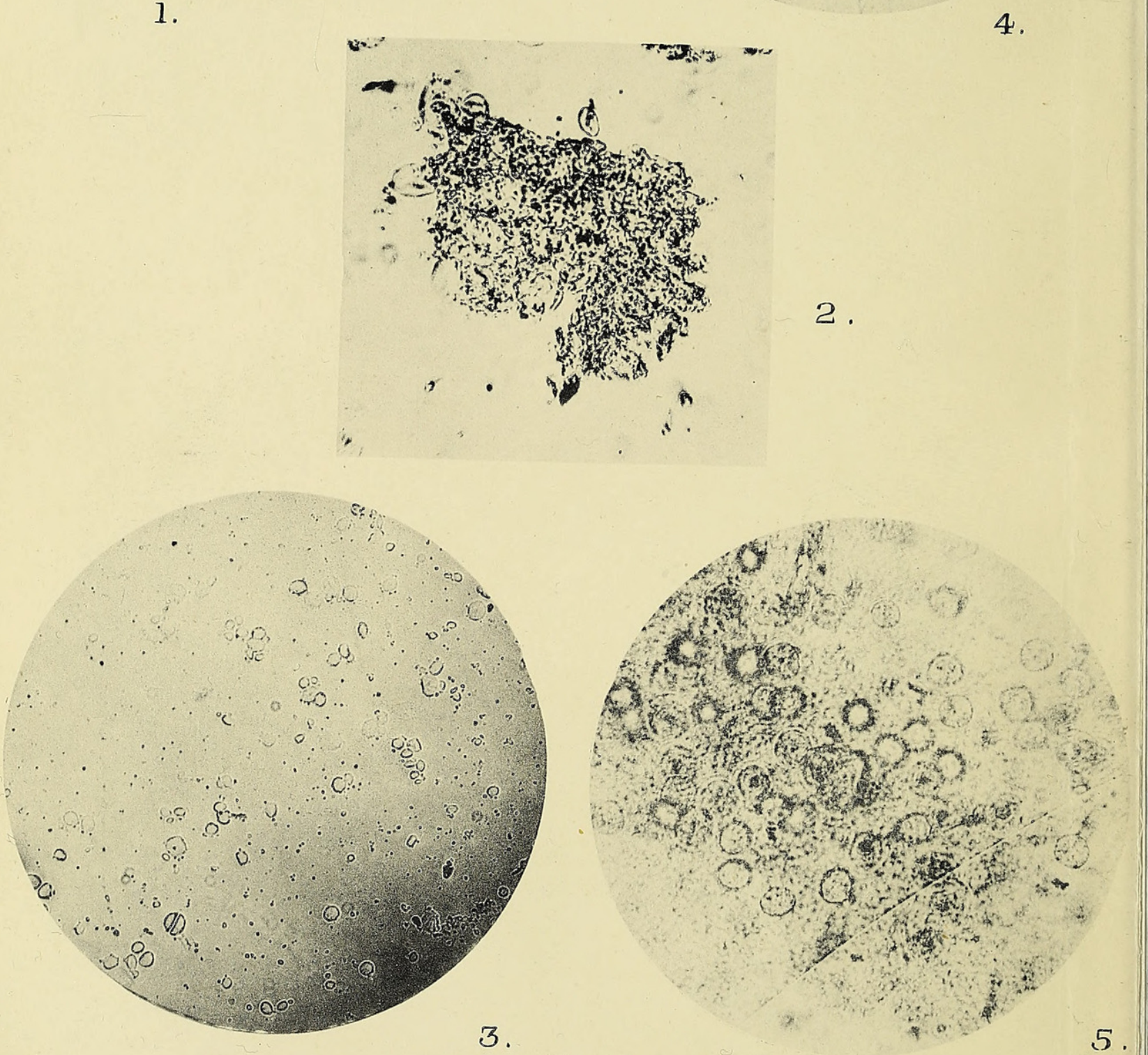

PAINE - COLLOIDAL SILICA. 


\section{$2 \mathrm{BHL}$ Biodiversity Heritage Library}

Paine, Sydney G. 1916. "On the supposed origin of life in solutions of colloidal silica." Annals of botany 30, 383-388.

https://doi.org/10.1093/oxfordjournals.aob.a089607.

View This Item Online: https://www.biodiversitylibrary.org/item/237452

DOI: https://doi.org/10.1093/oxfordjournals.aob.a089607

Permalink: https://www.biodiversitylibrary.org/partpdf/320124

\section{Holding Institution}

Smithsonian Libraries

\section{Sponsored by}

Biodiversity Heritage Library

\section{Copyright \& Reuse}

Copyright Status: Not in copyright. The BHL knows of no copyright restrictions on this item.

This document was created from content at the Biodiversity Heritage Library, the world's largest open access digital library for biodiversity literature and archives. Visit BHL at https://www.biodiversitylibrary.org. 